\title{
Liberalism in the Islamic World and its influence in the Malay Archipelago: Model in Indonesia
}

\author{
1Abbas Mansur Tamam \\ 1/bnu Khaldun University, Bogor, Indonesia \\ Email: abbas.mansur.tamam@yahoo.com
}

\begin{abstract}
Liberalism means here Orientalist attempt to attract even Islam conformity with the principles of Western liberalism in form and substance. Hence Zhardha in the Islamic world have to do Orientalism, which under his leadership became the U.S. currently wants Islam that corresponds to the values of modernity and secularism and Western liberalism. And this phenomenon coincides appearance in the Islamic world with its appearance Malay archipelago and Indonesia to face particular Alholanda since colonial days, and then taking this trend develops even have an influence on contemporary history in these islands. So this includes talking on two things: Orientalist role for the emergence of liberalism in the Islamic world, and its influence in the Malay islands.
\end{abstract}

Keywords:Liberalism, Islamic, liberal Orientalist, Secularism, Malay, Indonesia.

مقدمة

افترض الباحث أن انتشار المفاهيم الليبرالية للإسلام في العالم الإسلامي له صلة قوية بالاستشراق لأمرين:

أولا: لأن الاستشراق جزء من العقلية الغربية خصوصا فيما يتعلق بالشرق، لقد عبر إدوارد سعيد

(1935-2003) على ذلك في عنوان كتابه: 》الاستشراق المفاهيم الغربية للشرق《(1). وأن الشرق في المفهوم

الاستشراقي هو الإسلام على وجه التحديد، والعقلية الغربية بالتحديد هي الليبرالية.

ثانيا: يتعلق بالهيمنة الغربية وتأثيرها على الشرق، لأن الغرب الغالب يفرض مفاهيمه على الشرق

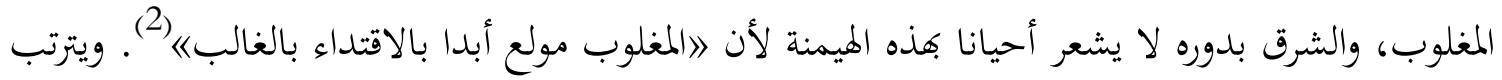
على ذلك تطبيق المبادئ الليبرالية على الإسلام ومحاولة تبرير الليبرالية بالنصوص الإسلامية.

الدكتوراة في العقيدة والفلسفة بجامعة الأزهر بالقاهرة، محاضر بالدراسات العليا بجامعة ابن خلدون بوجور، والمركز الدراسي للشرق الأوسط مات والإسلام-الدراسات العليا-جامعة إندونيسيا بجاكرتا.

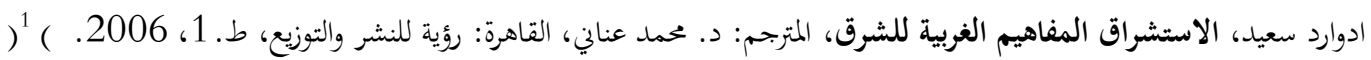




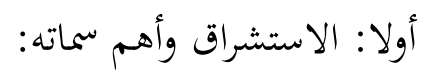

وبناء على ذلك فإن الحاجة ماسة إلى معرفة مفهوم الاستشراق وأهم سماته.

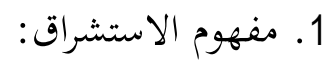

يعنى 》الدراسات الغربية المتعلقة بالشرق الإسالامي في لغاته وآدابه وتاريخه Orientalismالاستشراق وعقائده وتشريعاته وحضارته بوجه عامه|(3). ورغم أن اللفظ يشير إلى علاقة الدراسة بجوانب الشرق عامة إلا أن التطبيق الإجرائي والشائع في كتابات المستشرقين المعنيين تتصل تلك الدراسة بالشرق الإسلامي

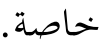

$$
\text { 2. 2 أهم سمات الاستشراق: }
$$

المفهوم البسيط للاستشراق هو أنه 》مبحث أكاديمي" (4)، لأن الإبجازات الاستشراقية تلبس ثوبا

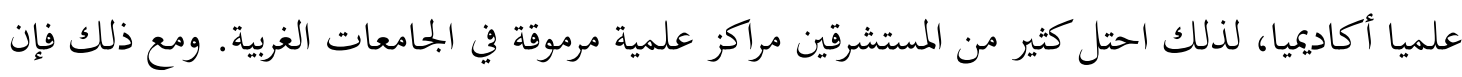
أغلب سماته وأهمها ثلاثة وهي: قياس الإسلام بالمسيحية، وأنه معرفة سياسية، ودراسة غير موضوعية. أ. قياس الإسلام بالمسيحية:

هناك ما يسمي بأوهام الجنس أو القبيلة، مفادها أن الناس \ميالون بالطبع إلى تعميم بعض

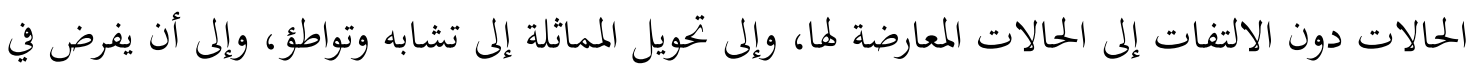

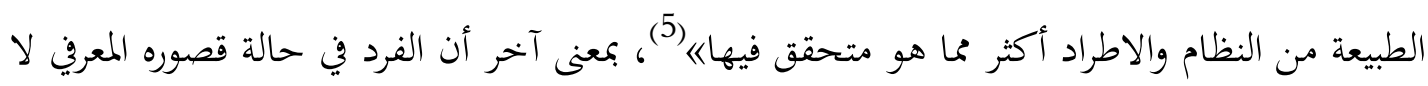
يستطيع أن يتجاوز حدود بحربته الخاصة.

وفي هذا الصدد كان المستشرقون محصورين بتجارهم الخاصة مع الدين المسيحي فينظرون إلى الإسلام مثل نظرتم إلى المسيحية جملة وتفصيلا ولجأوا إلى القياس أو التشبيه. وافترضوا أن محمدا للإسلام مثل المسيح للمسيحية، واطلقوا على الإسلام اسم 》المحمدية《) إيهاما أن المسلمين يألهون محمدا كما أهم

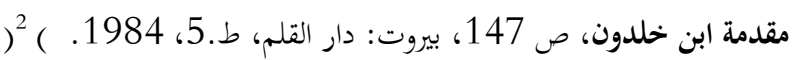

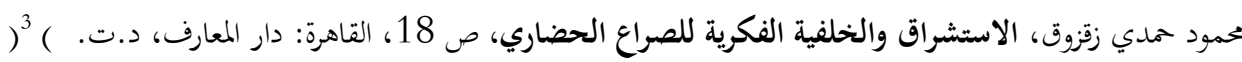

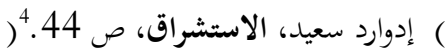

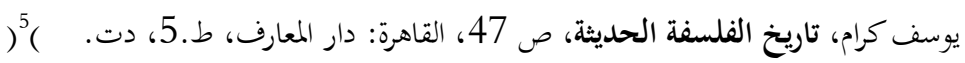


يألهون المسيح (6) وأطلقوا على العلماء اسم رجال الدين، وعلى الدولة الإسلامية اسم الحكومة الدينية. وعلى أثره 》انشأت صورة مسيحية للإسلام《|(7) وهي صورة وهمية ألقاها المستشرقون على الإسلام.

المعرفة صنفان: معرفة بحتة ومعرفة سياسية، والاستشراق هو معرفة سياسية. لقد صور ادوارد سعيد أن المعرفة عن الشاعر شيكسبير هي معرفة بحتة، لكن المعرفة عن الصين المعاصرة هي معرفة سياسية. لأن الأول بحال العلوم الإنسانية الذي ينفي وجود أي طابع سياسي في هذا البحال، وليس لها تأثير سياسي مباشر. بالعكس فإن الباحث المتخصص في الاقتصاد الصيني مثلا يعمل في بحال مشحون إلى أقصى درجة، والحكومة تبدي اهتماما كبيرا به، كما أن ما ينتهي إليه من دراسات أو مقترحات قد يستعملها راسمو

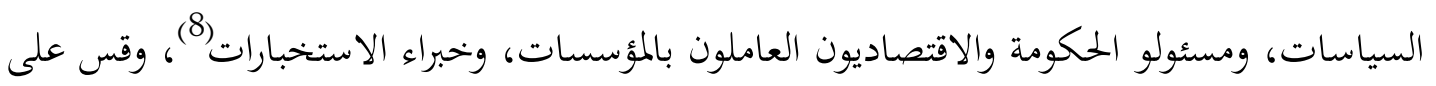
ذلك معرفة الغربيين عن الشرق الإسلامي.

ذلك لأن علاقة الغربيين بالشرق الإسلامي تتسم بالعداوة والكراهية. حيث هناك ثلاثة عوامل على الأقل جعلت من تفهم الغربيين للعرب والإسلام مسألة مشبعة بالدلالات السياسية العالية النيرة. الأول: هو تاريخ التعصب الشائع في الغرب ضد العرب والإسلام، الذي يتجلى واضحا في تاريخ الاستشراق.

والثاني: هو الصراع بين العرب والصهيونية الإسرائيلية، وتأثير ذلك الصراع في اليهود الأمريكيين وفي الثقافة المتحررة وفي السكان بصفة عامة.

والثالث: هو الانعدام شبه التام لأي موقف ثقافي يتيح للفرد التعاطف مع العرب أو الإسلام، أو مناقشة أيهما مناقشة غير انفعالية.

وهذا الجو المعادي للإسلام جعل اهتمام الغربيين بالشرق الإسلامي تلون باللون السياسي. قال أدوارد سعيد: اإن الاهتمام الأوروبي، تم الاهتمام الأمريكي، بالشرق كان اهتماما سياسيا..من المحال إنكار

راجع: مورس بوكاي، التوراة والأناجيل والقرآن الكريم بمقياس العلم الحديث، ص 19، ترجمةعلى الجوهري، القاهرة: مكتبة القرآن، (

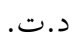

(إدوراد سعيد، الاستشراق، ص 126.

راجع: إدوارد سعيد، الاستشراق، ص 54. 
تأثر الدارس الأوروبي أو الأمريكي للشرق بالظروف الرئيسة لواقعه الراهن: أي أنه يتصدي للشرق باعتباره

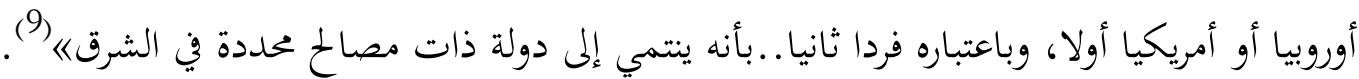
وإذا كان الأمر كذلك فإن الاستشراق في فاية الأمر رؤية سياسية للواقع.

إذا وصف الاستشراق بالمعرفة السياسية فإنه لا يرتكز على الموضوعية بل أصبح جزءا من النفعية البراجماتية الغربية التي أصبح معيار الصحة والبطلان هو نفعه أو مدافعته للمصالح الغربية بتحاه الشرق الإسلامي أو لا. وعلى هذا فإن الدراسات الاستشراقية بعيدة كل البعد عن الموضوعية أو المنهجية على لى لئل الرغم من أن المستشرقين أنفسهم يدعون موضوعيتها بشكل ممتاز .

ذلك لأغم يطبقون منهجا مقلوبا. لأن البحث العلمي يشترط فيه توافر النزاهة والأمانة والموضوعية، وهي التجرد عن الهوي والتعصب والغرور والبعد عن التجريح، ثم التمتع بالحيدة التامة والاعتماد على المصادر الأصلية مع القدرة على فهمها واستخلاص ما فيها. والعكس من ذلك فإن المستشرقين يضعون في أذهافم فكرة معينة يريدون تصيد الأدلة لإثباقا، وحين يبحثون عن هذه الأدلة لا قمهمم صحتها بمقدار ما يهمهم إمكان الاستفادة منها لدعم آرائهم الشخصية(10). كما أن دراساقمم تتسم بسوء الظن والفهم لكل ما يتصل بالإسلام في أهدافه ومقاصده، فيحرفون النصوص في كثير من الأحيان تحريفا

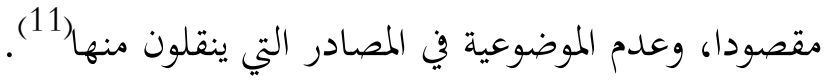

وإذا كان الأمر كذلك فإن الإنتاج الاستشراقي رغم أنه قد وصل إلى كمية هائلة من المؤلفات فإنها لا تعنى ضخامة الاستشراق وعظمته من زاوية الموضوعية، أي لا يعنى أهم أدركوا حقيقة الإسلام، بل العكس أن تلك الضخامة كانت بسبب بعدهم عن حقيقته، إذ اأن الجهل الغربي هو الذي ازداد في النهاية تنقيحا وبعدا عن البساطة، لا أن قدرا ما من المعرفة الإيجابية الغربية قد ازداد حجما ودقة. فالأكاذيب لها منطقها الخاص وجدليتها الخاصة)(12).

وعلى هذا علق الدكتور موريس بوكاي (1920-1998) بقوله: 》إن كثيرا من المسيحيين الذين تربوا

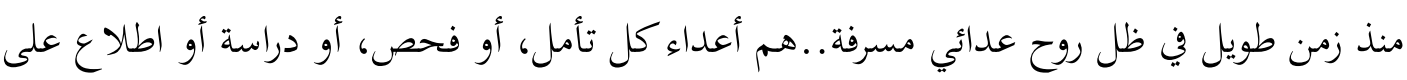

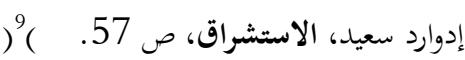

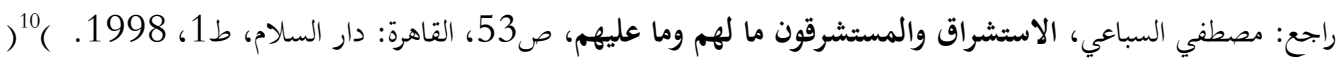

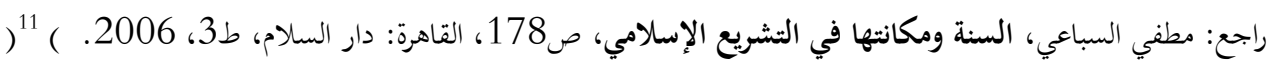

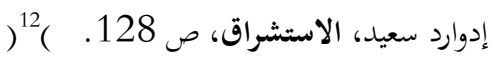


حقائق الإسلام وعقائده دون تحريف أو تزييف أو تشويه. إفهم بذلك يظلون في جهل مطبق يحول بينهم وبين فهم حقائق الإسالام، وبالتالي تظل مفاهيمه عن الإسلام مفاهيم غير صحيحة وغير مطابقة للحقائق دون ريب في ذلك《(13).

صحيح أن هناك فريقا من المستشرقين التزم في دراسته للإسلام بالموضوعية والنزاهة العلمية وأنصف الإسلام والمسلمين، وقد أدى الأمر ببعضهم إلى اعتناق الإسلام. ولكنهم للأسف الشديد نفر قليل جدا أقبلوا على الاستشراق بدافع من حب الاطلاع على حضارات الأمم وأدياها وثقافتها ولغاها، وهم غالبا لا يتلقون التمويل من الحكومة الاستعمارية. ومع ذلك فإن أكبر شريحة من المستشرقين يجرون وراء سراب يحسبه الظمآن ماء حتى إذا جاءه لم يجلده شيئا. ثنانيا: الدوافع الاستشراقية وزعامتها:

وإذا كان الأمر كذلك فلماذا أنفق المستشرقون كل إمكانياتم للحصول على نتائج غير موضوعية عن الإسلام؟ لا بد أن يكون هناك دوافع ملحة تحثهم على فعل شيء غير معروف، يتزعمهم أصحاب المصالح. وبالاطلاع على المصادر الاستشراقية تبين أهم هذه الدوافع هي الدافع الديني أو التنصيري والدافع السياسي أو الاستعماري، وكانت زعماء الحركة الاستشراقية هي الدول التبشيرية والاستعمارية.

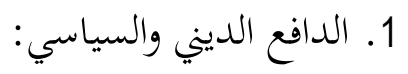

الدافع الديني كان لتحقيق الزعامة للمسيحية والانتصار لكل ما هو مسيحي، وتبلور هذا الباعث في حركة التنصير. وأما الدافع السياسي فلأن الصليبيين بعد أن هزموا في الحروب الصليبية أرادوا العودة إلى احتلال بلاد المسلمين من جديد فابتهوا لدراسة هذه البلاد في كل شؤوها بغية التعرف على مواطن القوة فيها فيضعفوها، وإلى مواطن الضعف فيغتنموها. ومن ثم فإنه يهدف إلى إضعاف المقاومة الروحية والمعنوية في نفوس المسلمين وبث الوهن والارتباك في تفكيرهم(14)، لذلك يسمي بالدافع الاستعماري.

ومن ثم فإن للاستشراق جناحين وهما التنصير والاستعمار . حيث قدم المستشرقون نتائج دراساهم ووصاياهم للمبشرين بغية تحقيق الأهداف التبشيرية، وللدوائر الاستعمارية بغية تحقيق الأهداف الاستعمارية.

موريس بوكاي، الثوراه والأناجيل والقرآن، ص 22.

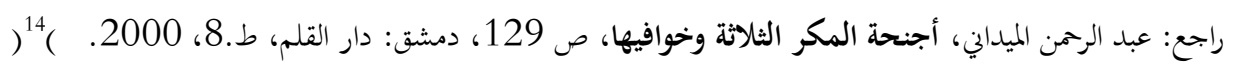


وإذا كان الأمر كذلك فإن 》القيمة الكبري للاستشراق تكمن في كونه دليلا على السيطرة الأوروبية الأمريكية على الشرق أكثر من كونه دليلا صادقا حول الشرق وهو ما يزعمه الاستشراق في صورته الأكاديمية أو البحثية) (15) 2. - 2. الزعامة الأمريكية للاستشراق:

يدور الاستشراق مع الاستعمار حيث دار. لذلك كان له جذور أوروبية متينة، لكن تحولت زعامته بتحول الزعامة الاستعمارية: المنذ بداية القرن التاسع عشر حتى فاية الحرب العالمية الثانية كانت لفرنسا وبريطانيا السيطرة على الشرق والاستشراق، وأما منذ انتهاء هذه الحرب فأمريكا هي التي تسيطر على الشرق وتتبع في ذلك المنهج الذي كانت تتبعه فرنسا وبريطانيا ذات يوم《) (16). 3. الإسلام الذي تريده أمريكا:

السؤال الملح الذي يفرض نفسه هو: ما الإسلام النموذجي الذي تريده أمريكا؟ في خمسينات القرن العشرين أجاب سيد قطب (1906-1966) عن هذا السؤال بقوله:

الالإسلام الذي يريده الأمريكان، وحلفاؤهم في الشرق ليس هو الإسلام الذي يقاوم الاستعمار، وليس هو الإسلام الذي يقاوم الطغيان ..الأمريكان وحلفائهم إذن يريدون للشرق 》إسلاما أمريكانيا《، يجوز أن يستفتى في منع الحمل، ويجوز أن يستفتى في نواقض الوضوء، ولكنه لا يستفتى أبدا في أوضاعنا الاجتماعية أو الاقتصادية أو نظامنا المالي، ولا يستفتى أبدا في أوضاعنا السياسية والقومية، وفيما يربطنا بالاستعمار من صلات. فالحكم بالإسلام، والتشريع بالإسلام، والانتصار للإسلام لا يجوز أن يمسها قلم،

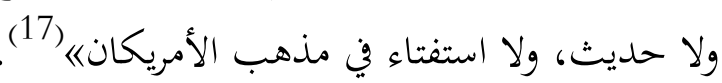

وظلت أمريكا تحارب لخلق هذا 》الإسلام الجديد) حتى قيل: 》إن حربا داخل الإسلام هي ضرورية لتحويله إلى إسلامحداثي..ليبرالي..علماني..وإن المدف من هذه الحرب داخل الإسلام هو تحويل التعليم

(إدوارد سعيد، الاستشراق، ص 50.

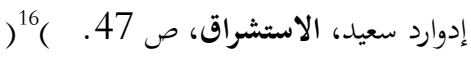

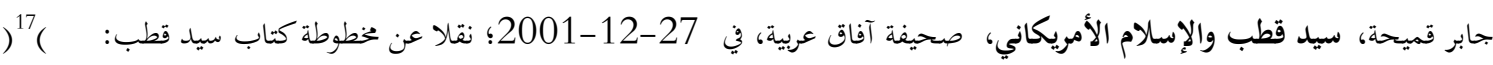

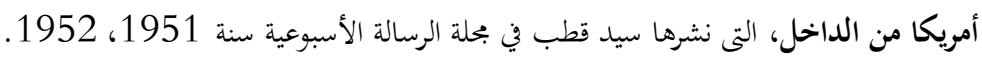


الإسلامي والخطاب الديني الإسلامي إلى طريق 》أتاتورك) (1881-1938) الذي أجبر تركيا بإصرار شديد على أن قُجر ماضيها!ي(18)

$$
\text { وهذا الإسلام الجديد هو ما يسمي عندهم بالإسلام المعتدل في مقابل ما سموه الإسلامي أو }
$$

الأمريكية بقولها: اإن (Research And Development Corporation) المتطرف. وقد عرفت مؤسسة راند

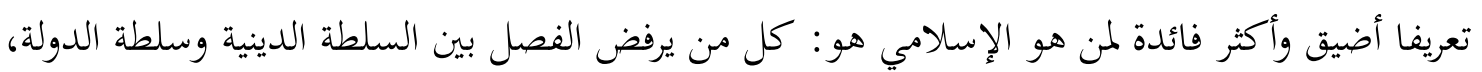

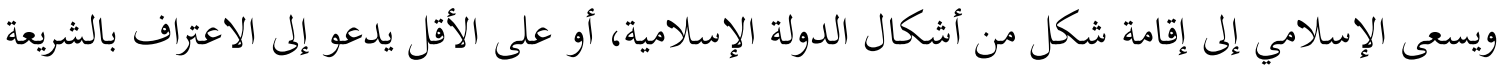
كأساس للتشريع《)

$$
\begin{aligned}
& \text { معنى ذلك أن الإسلام الذي تريده أمريكا هو الإسلام الذي يتطابق مع قيم الحداثة والعلمانية } \\
& \text { والليبرالية الغربية، حتى يتم كبت مقاومة السياسة الاستعمارية وإسكاتها. }
\end{aligned}
$$

ثالثا: الليبرالية في العالم الإسلامي: - n

وفيما يلي واقع بلورة هذا النموذج في العالم الإسلام.

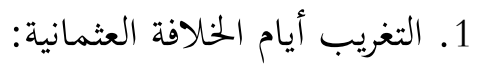

سجل السلطان عبد الحميد الثاني(1842-1918)في مذكراته السياسية عن التحرك الإنكليزي في

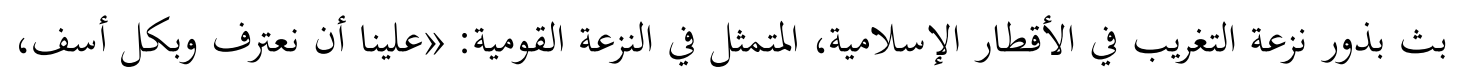

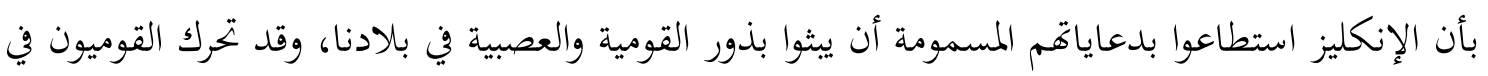

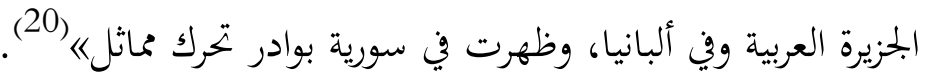

وبعد فترة تبنى بعض المسلمين هذه الفكرة وفضلوها على الإسلام:اييذل الإنكليز كل جهد ممكن

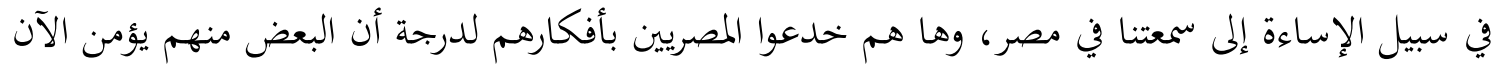

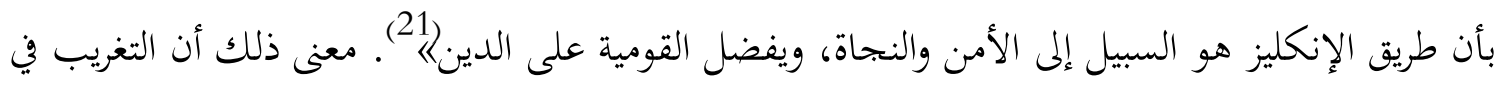

صحيفة الحياة، لندن، في 17-10-2003، وصحيفة الأهرام، القاهرة، في 18-10-2003. ) (ر

(19) Angel Rabasa And Others, Building Moderate Muslim Network, p. 75, Pittsburgh: Rand Corporation, 2007

عبد الحميد ين عبد البميد، مذكراتي السياسية، ص 177، بيروت: مؤسسة الرسالة، 1406.

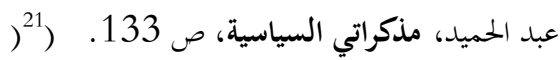


المخططات الغربية يقصد منه الكيد على الأمة الإسلامية وفقا لمطتلباتم الزمانية والمكانية، وأن بث النزعة القومية في ذلك الزمان يقصد منها تفكيك وحدة دولة الخلافة.

$$
\text { 2. نبذة عن الحركة الليبرالية في العالم الإسالامي: }
$$

وبمثابة التأريخ عن الحركة الليبرالية في العالم الإسلامي فقد قدم ألبرت حبيب الحوراني (19151993)تصنيفا لهذه الحركة وكان مرجعا لليبراليين، وهو في نفس الوقت موضع تساؤل عند الإسلاميين.

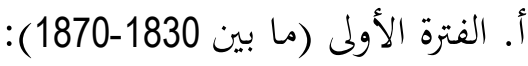

وهي فترة رأى فيها نخبة من المفكرين وأصحاب السلطة أن الصناعة والمؤسسات السياسية الأوروبية

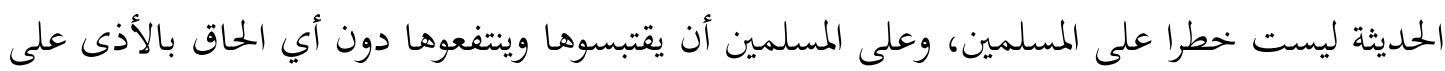
الهوية الدينية والحضارية للأمة(22). وبالتالي بدأت تنظر إلى العالم الغربي كحل لاستدراك تخلفهم الحضاريتي. وبدأت هذه الفترة بسفر الطهطاوي (1801-1873)إلى بارس، والذي ألف مذكراته عن النظام الاجتماعي في بارس 》اتلخيص الإبريز إلى تلخيص بارس《،، والأمير شكيب أرسلان (1869-1946) الذي ألف كتابه

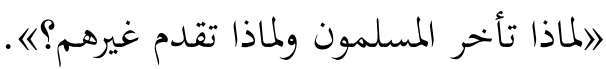
ب. الفترة الثانية (ما بين 1870-1900):

في هذه الفترة أصبح الغرب عدوا ونموذجا في نفس الوقت، لسيطرته على الدول الإسلامية من مصر والجزائر وتونس وامتد تأثيره السياسي إلى أرجاء الحلافة العثمانية. ودور المفكرين الليبرليين في هذه الحقبة هو إرشاد المحتمع بأن تأثير الحضارة الغربية على حياهم لا يجعلهم يفتقدون قيمهم الموروثة. لذلك قدموا فهما جديدا للإسلام ليتمشى مع الحياة الحديثة. ومن رموز هذا الجيل عند حوراني هو جمال الدين الأفغاني

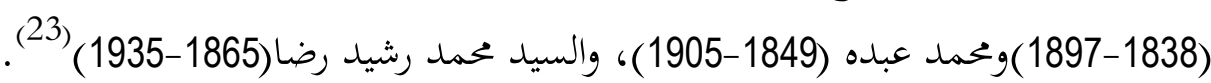
ج. الفترة الثالثة (ما بين 1900-1939):

تعتبر هذه الفترة قمة للتيار الليبرالي في الشرق الأوسط وفي مصر بالتحديد، وهي فترة مواجهة عنيفة بين ابتاهين: الأول يريد أن ينشئ البحتمع على أساس إسلامي ولذلك سماه الحوراني بالابحاه الأصولي.

${ }^{22}$ ) Albert Hourani, Arabic Thought in the Liberal Age 1798-1939, Indonesian Edition,translated by Suparno, Dahrits Setiawan, p. xxix-xxx, Bandung: Mizan, 2004. $\left.{ }^{23}\right)$ Albert Hourani, Arabic Thought, p. xxx. 
والآخر ذو الابتحاه الليبرالي الذي يريد أن يجعل الإسلام أساسا للحياة الفردية دون أن يتدخل في شئون البحتمع والدولة، وأن يكون المسيطر في البحال الثاني هو النظام العلماني. وتبلور هذا الاتحاه على يد طه حسين (1889-1973)الذي وصفه الحوراني بأن اأفكاره أكثر منطقيا في جعل القيم الإسلامية لتكون مقبولة في الفكر والنفوس، وفي إلحاحه على ضرورة جعل المسلمين في ركب الحضارة الغربية《(24).

وكان متحمسا لأن يلتزم المصريون بالقيم الغربية التي كانت في رأيه سلما يؤهلهم إلى سلك الأمم الراقية، وقال: 》السبيل إلى ذلك واحدة فذة ليس لها تعدد..وهي أن نسير سير الأوروبيين ونسلك طريقهم، لنكون لهم أندادا، ولنكون لمم شركاء في الحضارة: خيرها وشرها، حلوها ومرها، ما يحب منها وما يكره، وما يحمد منها وما يعابه"(25) كما رأي أن الاستقلال العقلي والنفسي لا يكون إلا بالاستقلال العلمي والأدبي والفني، ويتحقق ذلك بأن ا(نتعلم كما يتعلم الأوروبي...ولنشعر كما يشعر الأوروبي، ولنحكم كما يهكم الأوروبي، تم لنعمل كما يعمل الأوروبي، ونصرف ولحفي، ولحياة كما يصرفهاه (26). د. الفترة ما بعد الحرب العالمية الثانية حتى الآن:

يسمي الليبراليون هذه الفترة بالليبراليين الجحدد، حيث إفم يسيرون على نمط قدمائهم في الدفاع عن المصالح الغربية في الأمة الإسلامية، ويفكرون بطريقتهم. 3. غموض التصنيف الليبيرالي عند الحوراني:

بعد عرض موجز تلك الأدوار رأى الباحث أن هناك غموضا في تصنيف الحوراني لليبرالية. والأمر يثير قلقا شديدا حين بوأ الحوراني الأمير شكيب أرسلان، والأفغاني، ومحمد عبده، ورشيد رضا -وهمم فحول من الرواد المتحمسين بالإسلام، وأبلوا بلاء حسنا لنهضة الأمة الإسلامية، وهم المتضررون في سبيل ذلك باضطهاد المستعمرين عليهم- من الليبراليين وفي صف واحد مع طه حسين الممالي للاستعمار . مع أن البون شاسع بلا شك بين الاتجاه الممالي للاستعمار وبين مقاومه(27).

$\left(^{24}\right)$ Albert Hourani, Arabic Thought, p. xxxi.

طه حسين، مستقبل الثقافة في مصر، ج1، ص 45 45، القاهرة: دار المعارف، 1938.

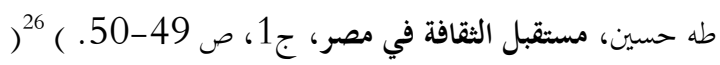

راجع: محمد البهي، الفكر الإسلامي الحديث وصلته بالاستعمار الغربي، القاهرة: مكتبة وهبة، ط. 14، 2005. 
وفي الحقيقة أن الحوراني متناقض إذ وضع لنفسه معايير لوصف مفكر ليبرالي. وتلك المعايير هي اأن يتكيف أي مفكر مع التطورات الغربية بمحاولته لتغيير البحتمع عن طريق تغيير النظام الاعتقادي والقيمي التي تخصهم، لتعطي هذه العقيدة والقيم بعد تغييرها شرعية قبول الأفكار والمؤسسات الأوروبية الحديثة)(28).

وهذه المعايير في رأي الباحث واضحة تماما، وإذا التزم الحوراني بها فإنه لن يدخل أحدا إلى زمرة الليبراليين إلا من اتصف بالتحرر من العقيدة والخصائص الإسلامية، وبذلك لن يكون الليبراليون إلا ملحدين أو ارتيابين. ومن ثم فإن تناقضه واضح حينما وصف الأمير أرسلان، والأفغاني، وعبده ورشيد رضا بأفم ليبراليون مع أن التزامهم بالعقيدة والشريعة الإسلامية أمر لا شك فيه.

والقول بأن وصف الليبرالية لا يطلق إلا من يتحرر من العقيدة والخصائص الإسلامية ليس بدعا من الباحث، بل صفة وصفها اللورد كرومر، وهو من أكبر رائد في تغريب مصر والعالم العربي،على هؤلاء الليبراليين إذ قال: 》إن المجتمع المصري في مرحلة الانتقال والتطور السريع، وكانت النتيجة الطبيعية أن وجدات جماعة من أفرادهم 》امسلمون《 ولكنهم متجردون عن العقيدة الإسلامية والخصائص الإسلامية، وإن كانوا اغربيين《)فإفم لا يحملون القوة المعنوية، والثقة بأنفسهم، وإن المصري الذي خضع للتأثير الغربي، فإنه وإن كان يحمل الاسم الإسلامي لكنه في الحقيقة ملحد وارتيابي، والفجوة بينه وبين عالم أزهري لا تقل عن الفجوة بين عالم أزهري وبين أوروبيها (29).

لذلك فإن تصنيف الحوراني لليبراليين يثير شكا واضطرابا واضحا، وقد عبر هو نفسه صراحة أنه

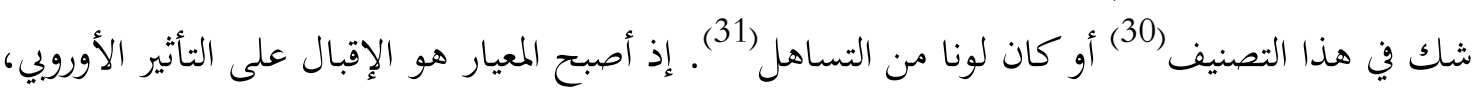
دون أن يفرق بين أن يكون الفكر توفيقيا فيكون تجديدا إسلاميا أم تغريبيا؟ وقد جعل اثنين في واد واحد.

بكورة الظاهرة الليبرالية بإندونيسيا كانت موجودة منذ عصر الاحتلال الهولندي، الذي تزامن مع ظهورها في العالم الإسلامي، ثم تتطور تلك الظاهرة مع مرور تأثير الثقافة الغربية في البلاد.

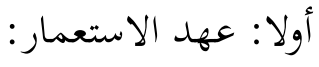

$\left(^{28}\right)$ Albert Hourani, Arabic Thought, p. xxvii.

$\left.{ }^{29}\right)$ The Earl of Cromer, Modern Egypt, Vol. II, p. 228-229, New York: Macmillan, 1908.

$\left(^{30}\right)$ Albert Hourani, Arabic Thought, p. xxxv.

$\left(^{31}\right)$ Albert Hourani, Arabic Thought, p. xxvi. 
اختلف المؤرخون في دخول الإسلام إلى الأرخبيل الملايوية، فمنهم من أرجعه إلى منتصف القرن

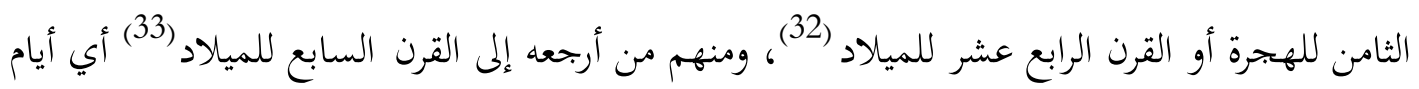

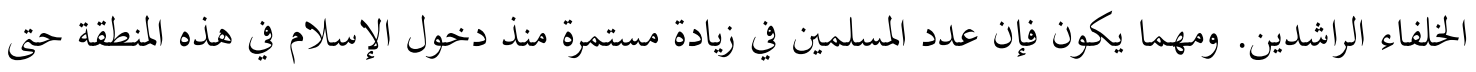
تعتبر إندونيسيا حاليا أكبر دولة مسلمة في العالم من حيث الكثافة السكانية. وكان من أبرز المواقف الاستعمارية إزاء الأمة الإسلامية فيما يتعلق بالفكر الإسلامي ما يلي:

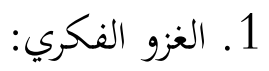

لا بد من توضيح مفهوم الغزو الفكري قبل ذكر الحقائق التاريخية التي رسمها الاستعمار.

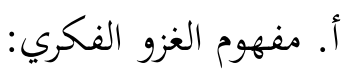

الفكر عامة يتعلق بأحد أمرين: يتعلق أولا 》بمشترك إنساني عام) ويتعلق ثانيا 》بخصوصية

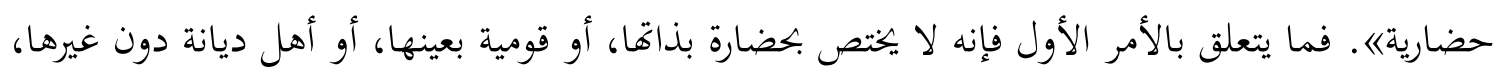

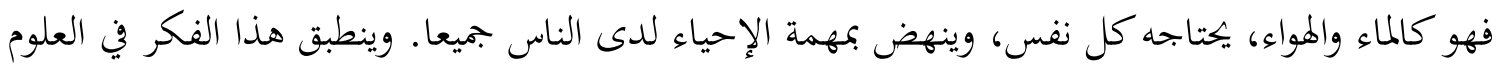

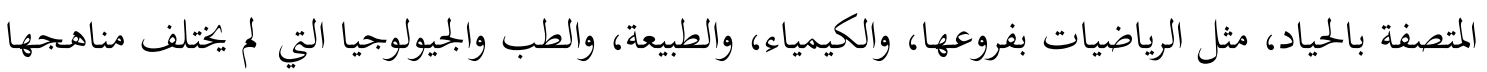
وحقائقها وقوانينها باختلاف الحضارات(34).

وفيما يتعلق بالأمر الثاني فإن الفكر يتمايز بتمايز الحضارات. فالنفس الإنسانية التي تتميز مكوناها

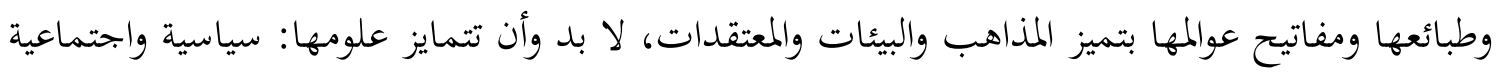

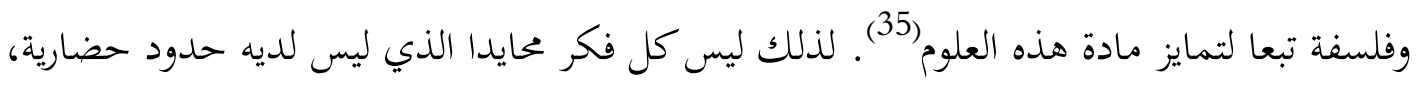
ولكن كل حضارة لما سماتما وخصائصها تختلف بين حضارة وأخرى لأهما تمثل بطاقاها الشخصية.

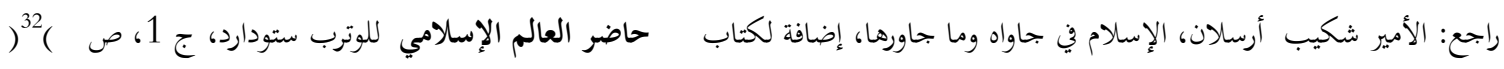
338، بيروت: دار الفكر، د.ت.

(33) See: Azyumardi Azra, Jaringan Ulama Timur Tengah dan Kepulauan Nusantara Abad XVII dan XVIII (شبكات علماء الشرق الأوسط والجزر الإندونيسية في القرن السابع عشر والثامن عشر), p. 23-50, Bandung: Mizan, 1995.

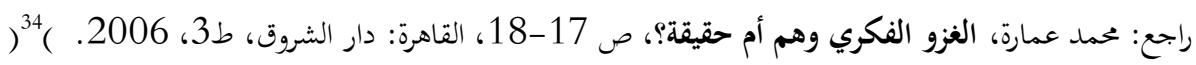

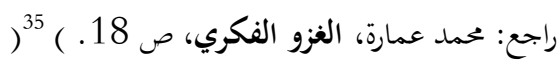


ومن ثم فإن الغزو الفكري هو: الضغوط من حضارة إلى أخرى ببعض الأفكار التي تتنافر مع هويتها الحضارية(36)

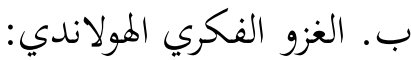

صاحب الريادة في الغزو الفكري الهولاندي كان على أيدى سنوك هورخرونيه(1857-1936) المستشار

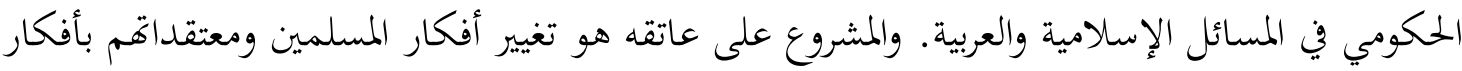

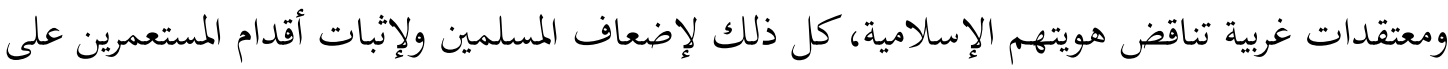
رؤوس المواطنين.

أراد سنوك أن يصبح الإسلام 》دين المسجده/ مثل كون المسيحية دين الكنيسة، وأن يجعل الإسلام دينا

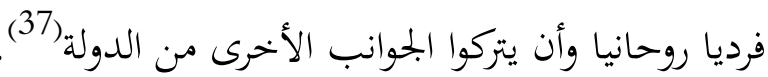

كما أراد أن يهول الشعب الإندونيسي إلى وطنيين هولانديين بشرط تركهم عرى الإسلام من فكرة الاتحاد

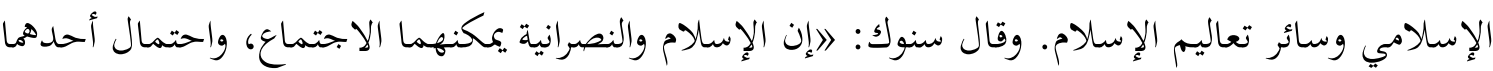

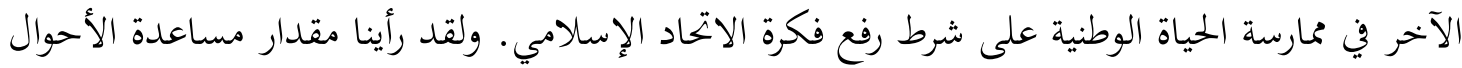

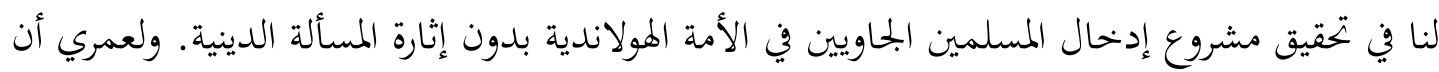
كثيرين منا يمكنهم أن يأخذوا دروسا من التساهل الديني عن أولئك الأهاليه (38).

وشدد سنوك على ضرورة اتخاذ الحكومة إجراءات ممكنة لتحويل الإندونيسين إلى الثقافة الغربية حتى تتغلب

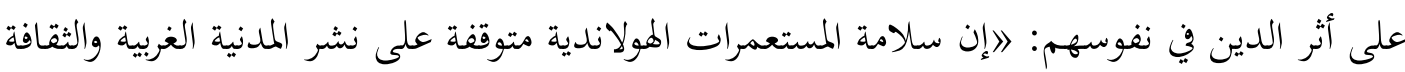

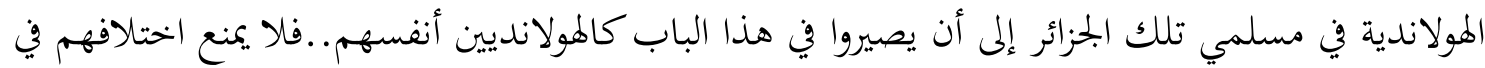

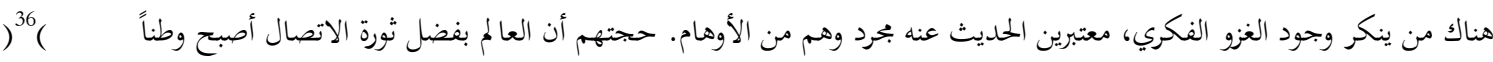

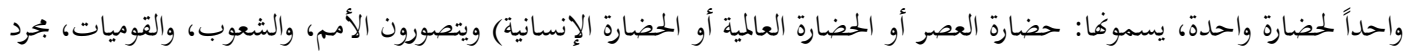

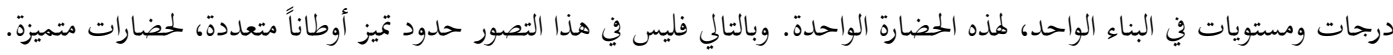

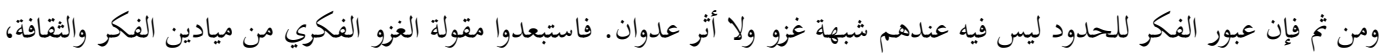

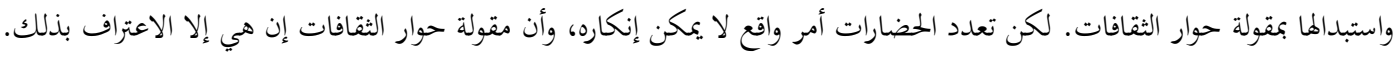
فالتعددية لا الواحدية، هي الحقيقة الممثلة للواقع الحضاري الذي نعيش عليه. ومن ثم فإن هناك الكات حالات لتعدي الحدود الحضارية، تمثل غزواً فكريا لا شك فيه.

$\left.{ }^{37}\right)$ Boland, The Struggle of Islam in Modern Indonesia, Indonesia Edition (Pergumulan Islam di Indonesia 1945-1970), p. 16, translated by: Safroedin Bahar, Jakarta: Grafiti, 1985.

نقلاعن الأمير شكيب، حاضر العالم الإسلامي، ج1، ص 344-345. (38) 
الدين مع مسلمي الجاوى وسومطرة أن يكون هؤلاء في يوم من الأيام وطنيين هولانديين، وذلك بحمل هؤلاء على الثقافة المولاندية التي تتغلب في نفوسهم على أثر الدينهاء (39).

ورأي سنوك أن طريقة أكثر فعالية لفرض الثقافة الغربية على الشعب ومحو أثر الدين في نفوس المسلمين هي عن طريق التربية والتعليم على النمط الهولاندي.

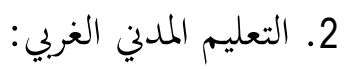

قررت الحكومة الهولاندية على إعطاء التعليم لأبناء الشعب بعد أن كان محروما عنه، ويسمي هذا القرار

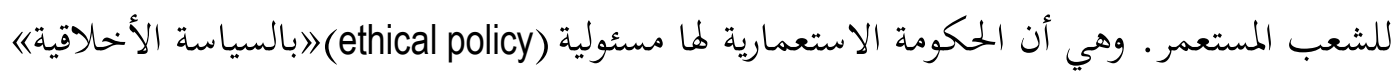

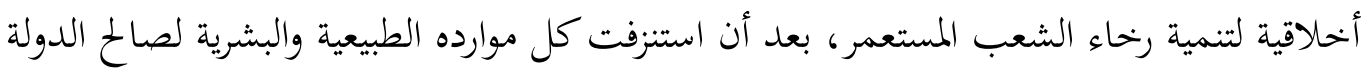
المستعمرة، ومن بنود هذه السياسة هي تطوير التربية والتعليم.

لقد كان الشعب طوال قرون ثلاثة على جهل مطبق في أمور دنياهم، وليس بينهم في تلك المدة المديدة

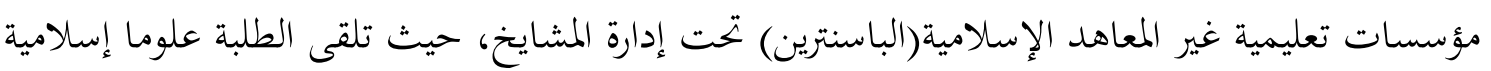

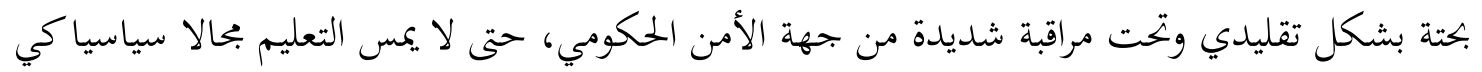
لا يكون مصدرا للقلق على الحكومة المستعمرة.

لكن هذه السياسة كانت بمثابة سلاح ذي حدين، إنها أدت أولا إلى تنمية الكفاءة البشرية، أها ثانيا أداة للحكومة المستعمرة لعملية التحول الثقافي والمعنوي للشعب. وعلى هذه المهمة أرسلت الحكومة بعض أبناء الشعب للبعثة الدراسية إلى المدارس والجامعات في هولنده: 》أن الموظفين الهولنديين في المناطق الإندونيسية المعاية أخذوا بعض شباب من أصحاب المواهب ليدرسوا في الجامعات الهولندية، حرصا منهم على إعطاء التعليم

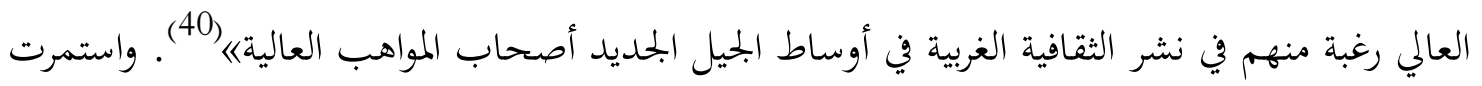

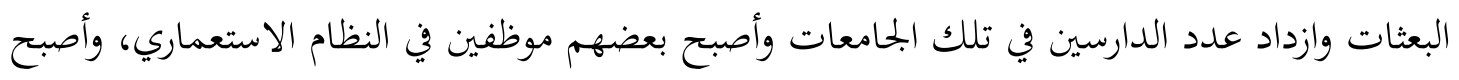
البعض الآخر رمزا للمقاومة حتى استقلال البلاد سنة 1945.

3. الصراع بين الإسلاميين والعلمانيين:

نقلا عن المصدر السابق، ج1، ص 342.

( ${ }^{40}$ ) Harry A. Poeze, Indonesian at Leiden University, in Indonesian and Islamic Studies, p. 34, Zaini Muchtarom, Jacob Vredenbregt, E. Van Donzel (ed.), Jakarta: Indonesian Netherlands Cooperation in Islamic Studies (INIS), 1990. 
هناك صراع بين الإسلاميين والعلمانيين من أيام الاستعمار، ولا تزال هذه المواجهة قائمة بين الإسلاميين والليبراليين حتى اليوم.

والشعب أيام الاستعمار ثلاث فئات: النبلاء، والوطنيون العلمانيون، والوطنيون المسلمولن

تكوَّن النبلاء من الأشراف والملوك ورؤساء القبائل الذين كان لهم حظ ثقة الحكومة الهولاندية. وسبب نيل هذه الثقة لأن بعدهم عن الإسلام جعلهم غير آبهين بظروف الشعب، وهم انتهازيون ومستعدون للخضوع تحت أوامر حكومية على حساب إخواهم من الشعب، خيانة للمصالح الوطنية. لذلك اعتمدت عليهم الحكومة في أكثر فترة الاحتلال تمتد ثلاثة قرون ونصف قرن من الزمن. وانتهت هذه المكانة مع بجيئ

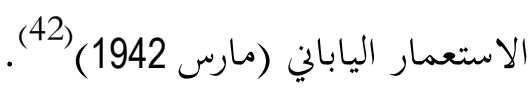

والإسلاميون نافسوا العلمانيين خاصة في عهد الاستعمار الياباني الذي امتد ثلاث سنوات ونصف، وأخذوا مكانة هامة في هذا العهد، حيث انحازت اليابان إلى الفئة الدينية رغبة منها في المساندة والمواجهة ضد التحالف الغربي في الحرب العالمية الثانية، إدراكا منها أن المسلمين أكبر شريحة في المحتمع الإندونيسي: 》اليابانيون نظروا إلى الإسلام أنه أهم وسيلة لنيل التعاطف من الشعب الإندونيسي، ولتكون هذه العاطفة راسخة في نفوسهم. وبهذا المنطق انحاز اليابانيون إلى المسيحية في الفلبين وسيلة للتأليف الأيدولوجي" (43). ثانيا: سوكارنو بين السلفية الإصلاحية والتحديث الإسلامي:

الإشارة إلى الاتحاه الفكري للرئيس سوكارنو ستكشف الجذور الليبرالية في فترة ما بعد الاستقلال، لأنه كان أبرز شخصية سياسية وفكرية في نفس الوقت، حيث مقالاته المدونة في كتابه 》تحت راية الثورة《 أبدت اهتمامه البالغ بالإسلام. ذلك أن ثمة ابتحاهين للتجديد الإسلامي في هذه الفترة: السلفي الإصلاحي، والتحديث الإسلامي.

1. 1 المدرسة السلفية التجديدية: - 1

(11) See: Boland, B.J, The Struggle of Islam in Modern Indonesia (1945-1972), Indoenesian Edition (Pergumulan Islam di Indonesia 1945-1972, p. 9, Jakarta: Grafiti, 1985.

${ }^{42}$ See: Boland, The Struggle of Islam in Modern Indonesia, p. 9-10.

(3) Boland, The Struggle of Islam in Modern Indonesia, p11. 
في فترة الخمسينات من القرن العشرين ساد التخلف في جميع بحالات الحياة بإندونيسيا، خصوصا وأها

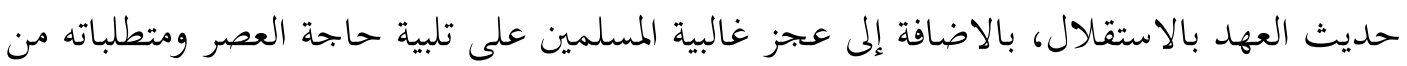

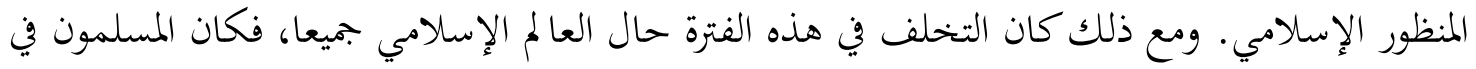

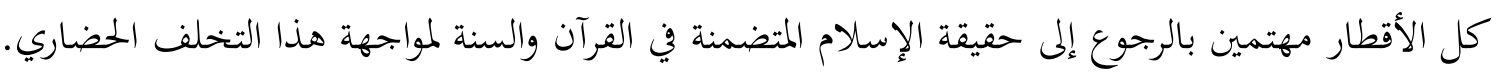

تأثر المسلمون بإندونيسيا بالحركات التجديدية الموجودة في الشرق الأوسط بفضل الحجاج والطلبة الذين

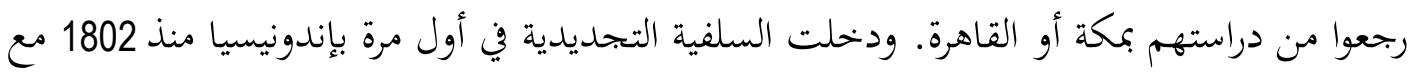

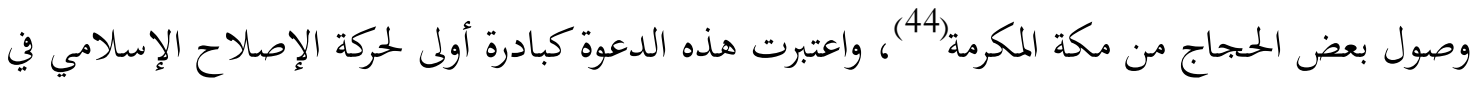

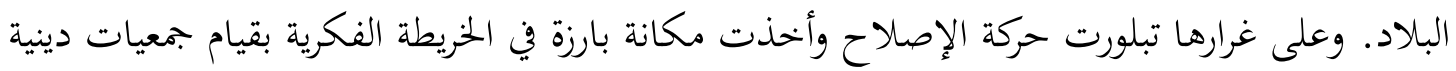
واجتماعية في مطلع القرن العشرين.

ويعتبر قيام 》جمعية خيرية) سنة 1905 في جزيرة جاوى أول هذه الجمعيات على الإطلاق، ومن دائرتا

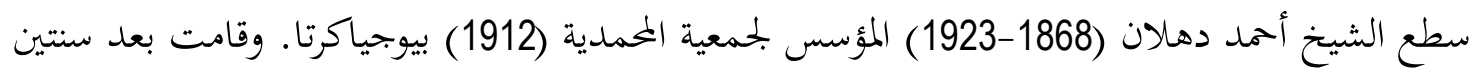
(1914) جميعة الإسلام والإرشاد بجاكرتا، ثم جمعية الاتحاد الإسلامي (1923) بباندونج. كل هذه الجمعيات

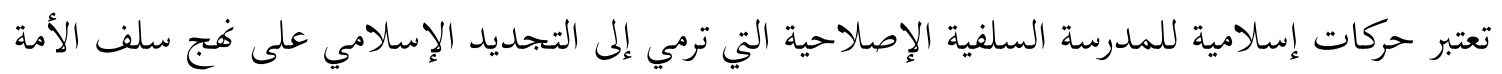

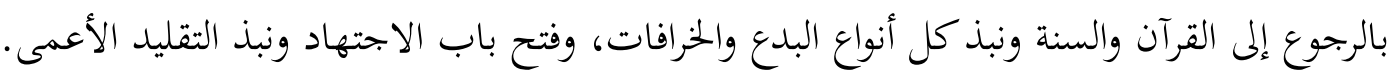

$$
\text { 2. (التحديث الإسلامي لسوكارنو: }
$$

أما الاتحاه الأخر من التجديد فإنه حاول على مسايرة الحياة العصرية، والأخذ بالصالح من منظور النظام

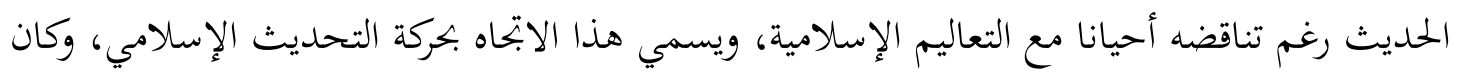
سوكارنو أبرز شخصية لهذا الابتحاه.

وفي احدى مقالاه المنشورة في راية الإسلام رأي ضرورة بحديد مفهوم الإسلام، ويقصد به تفكيك مفاهيم

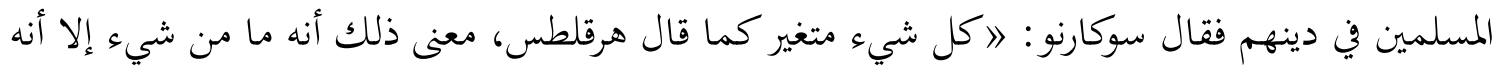

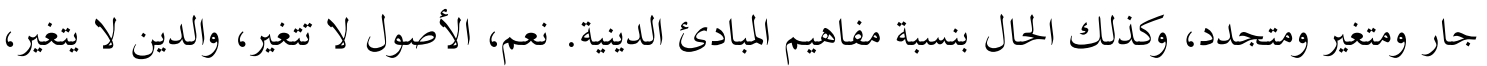
والإسلام الحقيقي لا يتغير، وكلمات الله وسنة نبيه × لا تتغيران، ولكن الفهم الإنساني لهذه الأشياء يتغير.

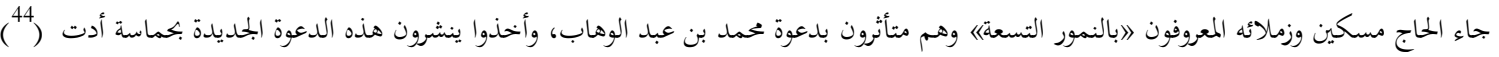

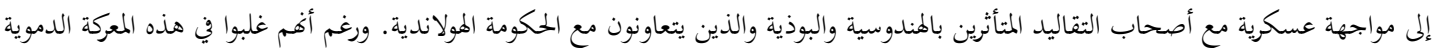
مدة 15 سنة (1822-1837) إلا أن آثارهم باقية، وتعليمهم مستمر، وتولدت من هذه الحركة الدعوية علماء كثيرة. راجع: نهضة العالم

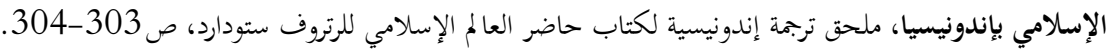


إنه يتطلب ضرورة وجود نقد هذا المفهوم بصفة دائمة، وحقيقة هذا النقد هي الاجتهاد أو البحوث الذي

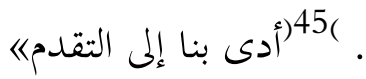

العبارة بأن 》اكل شيء متغير) هي مفتاح الابحاه الفكري لسوكارنو وهو نفس الابحاه الليبرالي حاليا. وبرغم

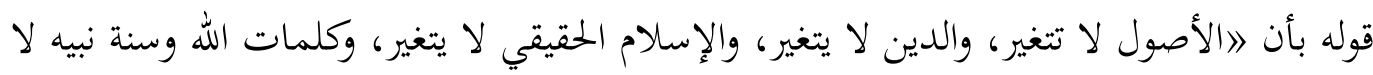
تتغيران《، فإن هذه المقولة أصبحت كلمات خطابية إذ علق أن 》الفهم الإنساني لهذه الأشياء يتغير《، وهو يقصد أن كل ما يفهمه الناس في الأصول والفروع متغير. وبمقتضاه يجوز في رأيه أن يختلف المسلمون في فهم كل ما يتعلق بدينهم.

ورأى أن اختلاف الظروف والملابسات بين قطر وآخر يؤدي إلى الاختلاف الفكري، من أجل ذلك فإن الفكر الإسلامي في تركيا قد يختلف عما هو في مصر أو في الهند. لذلك دافع عن شرعية الفصل بين الإسلام والدولة في تركيا، لظروفها الثقافية والسياسية، وقال: الي سنة 1928 تم محو الكلمات الموجودة في الدستور التي نصت أن الإسلام دين الدولة، وأصبح الدين فيما بعد أمورا شخصية. إنه لم يمح الإسلام من

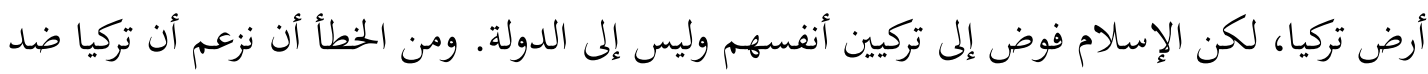
.

وهذا التبرير إن دل على شيء فإنه يدل على قناعته الفكرية بالعلمانية، وإلا فكيف يقال بأن ما حدث بتركيا في تلك الفترة ليس ضد الإسلام، وقد أصبحت الدولة علمانية، وأن الدين شخصية لا دخل له في السياسة والإدارة، وألغيت المحاكم الشرعية والقانون الإسلامي، وصدق القانون المدني السوسري، والقانون الجنائي الإيطالي، والقانون التجاري الألماني، ومنع التعليم الديني، وعطل مراكزه، ومنع الحجاب، وألغى الحروف العربية وأبدلها بالحروف اللاتينية، ومنع الآذان بالعربية وجعله بالتركية، وغير اللباس وألزم لبس القبعة.

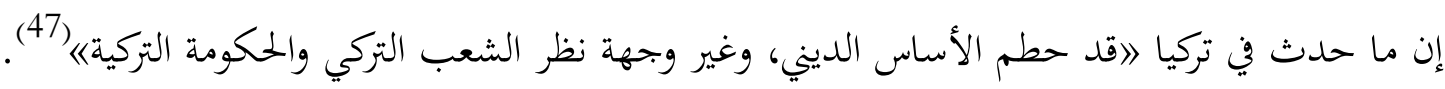
لقد أصبحت تركيا غير إسلامية، حيث أسقطت كل ما يتعلق بالإسلام وحاربت كل المعالم الإسلامية.

والغريب أنه وصف ما فعله أتاتورك بأنه دفاع عن كرامة الإسلام، كما أنه هيئ له أرضا خصبا في أرض

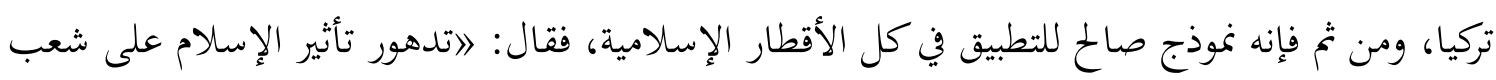

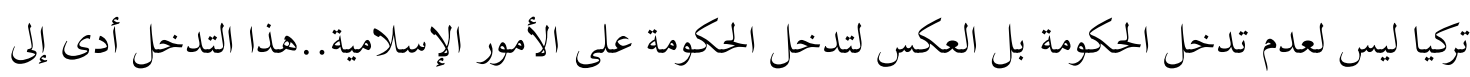

(45) Sukarno, Dibawah Bendera Revolusi (تحت راية الثورة), vol. 1, p. 370.

(ت) Sukarno, Dibawah Bendera Revolusi (تحت راية الثورة), vol. 1, p. 377.

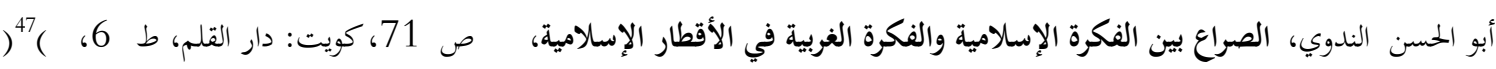
.2003 
》تقييد أيدي الإسلام وأرجله| بالسلاسيل السياسية. لذلك فإن إدارة الحكومة للشئون الإسلامية أدت إلى

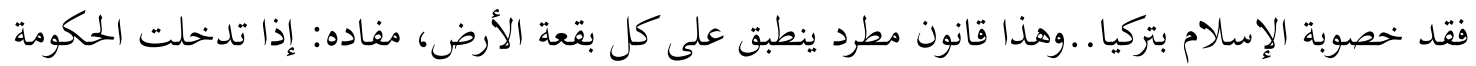

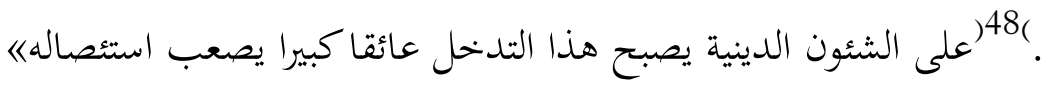

فكما أثنى على علمنة تركيافإنه قدر رسالة علي عبد الرازق (1888-1966) 》الإسلام وأصول الحكمه بأن

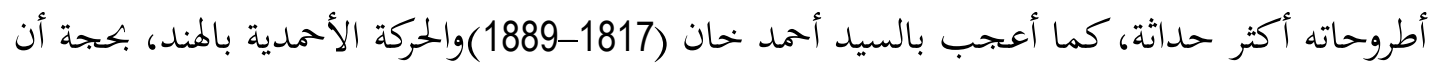

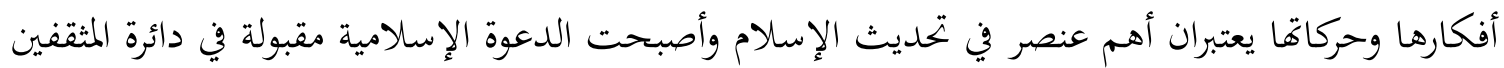

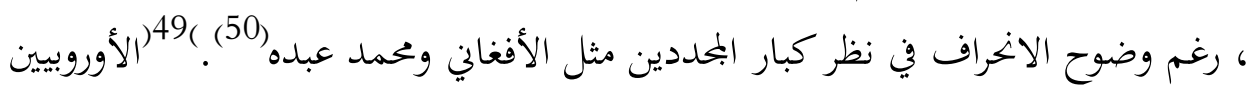

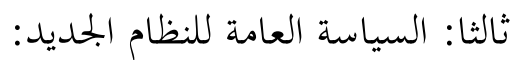

شهدت إندونيسيا أسود تاريخها بالثورة الدموية للحزب الشيوعي الإندونيسي (30 سبتمبير 1965) حيث

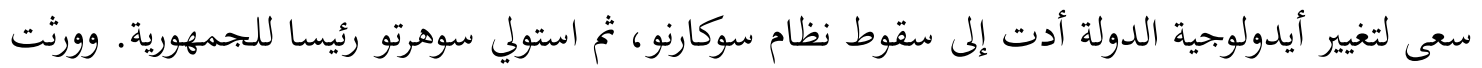

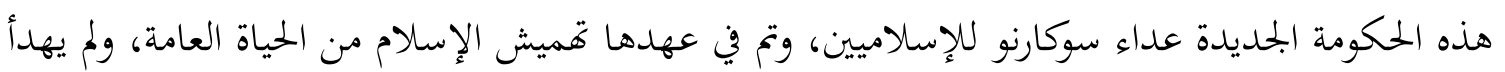
هذا العداء إلا في آخر مرحلتها. وتمحورت السياسة العامة للنظام سوهارتو في ثلاثة خطوط رئيسة وهي

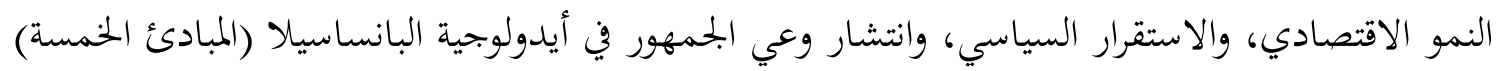

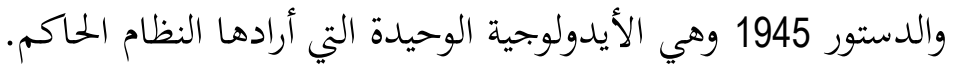

من أجل هذه المحاور الثلاثة حارب سوهرتو كل الحركات والاتحاهات الإسلامية. علة ذلك خشيته على أن يظهر الإسلام قوة جديدة في المسرح السياسي بعد حل الحزب الشيوعي. لقد عبر سومترو (1927-1998) عن هذه المخاوف بقوله: ابعد أن استولي النظام الجحيد على السلطة. .أدرك النظام أن الفرصة سانحة لعودة النفوذ السياسي للإسلام. لأن سقوط الحزب الشيوعي وحل أيدولوجيته قد يساعدان الإسلاميين لذلك الذكانك

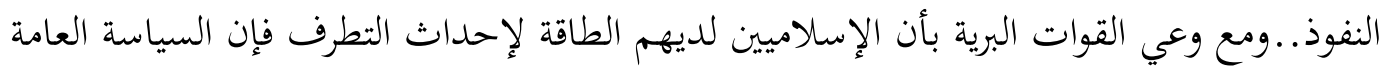

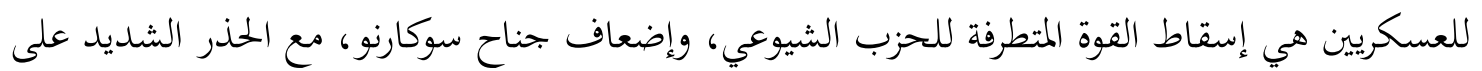
طلوع الجناح الإسلامي" (51).

(8) Sukarno, Dibawah Bendera Revolusi (تحت راية الثورة), vol. 1, p. 378.

(79) See: Sukarno, Dibawah Bendera Revolusi (تحت راية الثورة), vol. 1, p. 388-389.

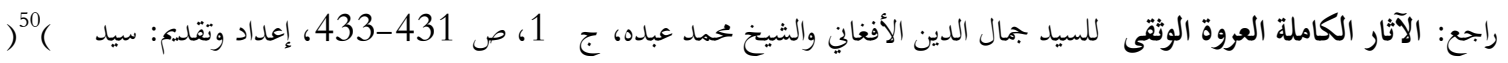

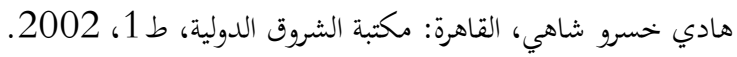

(1) Heru Cahyono, Soemitro dan Peristiwa 15 Januari 1974 (سومترو وأحداث 15 يناير 1974), p. 46, Jakarta: Pustaka Sinar Harapan, 1998. 
مع هذا التوافق بين الحاكم والقوات البرية على محاربة الإسلاميين صار النفوذ السياسي للعلمانيين والمسيحيين هو المهيمن على الأوضاع كلها في البلاد. وقد نشط النظام طوال عشرين عاما (1967-1987) لمنع الظهور الأيدولوجي للإسلام، وجاهد لتهميش المسلمين من السياسة، وإقامة الحياة العلمانية في شتى لهائ الميادين، كل ذلك خوفا من الإسلام وهو المعروف بإسلاموفوبيا.

وهذه السياسة العامة لها انعكاساتحا بالضرورة في سياسة وزراء الدولة وجميع المؤسسات الحكومية الواردة تحتها، وبهذا الصدد وزارة الشئون الدينية والجامعات الإسلامية النظامية. الأن تلك الجحامعات وهي من المؤسسات الحكومية تأثرت بشكل مباشر بالاتحاه السياسي للحكومة. لأن قيادة تلك الجامعات ولون سياساتها تتعلق بوزير للشئون الدينية《(52).

(وهي حزب النظام الحاكم في الانتخابات العامة عام Golkar،لذلك بعد أن فازت 》الفئة المشتغلة《) كان أولي برابحه تغيير سياسة هذه الوزارة. وتم هذا التغيير في ثلاثة خطوط رئيسة وهي: تغيير الوظائف حتى تتناسب مع السياسة العامة التي رآها؛ وتعيين الشخصيات من غير فئة تقليدية كانوا من الهامشيين في عهد

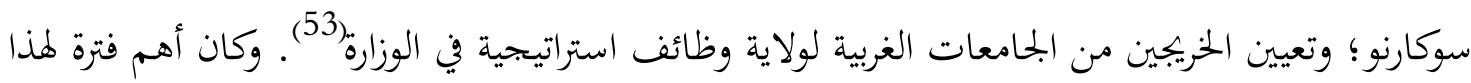
التاريخ فترة وزارة الدكتور عبد المعطي علي (1971-1978) ووزارة منور الشاذلي (1983-1993).

وفي عهدهما تم تغيير التحاه النظام التعليمي للجامعات الإسلامية النظامية بإندونيسيا على درب الجامعات الغربية. لقد تغيرت الجحامعة من كوها مؤسسة دعوية وتعليمية إسلامية إلى كوفا مؤسسة علمية بحتة بمعيارها التاريخية والتجريبية. وفي كتاب 》الجامعة الإسلامية النظامية والتحديث الإسلامي بإندونيسيا《 ناقش مؤلفه قضية العلاقة بين الدور الدعوي والعلمي للجامعة. مبدئيا افترض أن لا يتناقض هاتان الوظيفتان وكانتا معا في الاتحاه التعليمي، والأمثل أن تكون مادة الدعوة حقيقة علمية. لكنه يبرر ميل الجامعة إلى كوفا مؤسسة علمية وخلعت عن وصفها مؤسسة دعوية، لأن الوظيفة العلمية في رأيه أجل من الدور الدعوي، ومن غير لائق لجامعة راقية، حسب رأيه، أن تلعب هذا الدور(54) المنطلق من الجانب العقيدي الأيدولوجي.

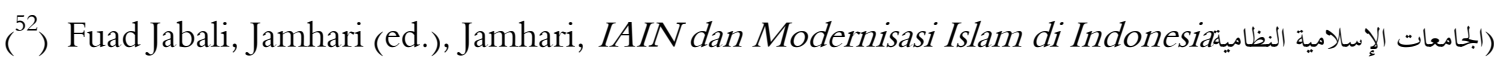
وتحديث الإسلام بإندونيسيا), p. 16, Jakarta : Logos, 2002.

${ }^{53}$ ) See: Fuad Jabali, IAIN(الجامعات الإسلامية النظامية وتحديث الإسلام بإندونيسيا), p. 18.

$\left(^{54}\right.$ See: Fuad Jabali, IAIN(الجامعات الإسلامية النظامية وتحديث الإسلام بإندونيسيا), p. x. 
والفرق بينهما أن الدور الدعوي، في نظر مؤلفه، أيدولوجي بالدرجة الأولي، لأن الدعوة دائما تنطلق من الدعوى بحقيقة الإسلام وببطلان غيره من الأديان، وهي تتنافي مع الصفة العلمية، لأن الوصف العلمي يتطلب عدم التحيز إلى عقيدة ما، كما ينبغى أن يتحرر من المعيار العقائدي حتى لا تكون النتيجة مقيدة بالأفكار المسبقة. ولذلك يعدلون المناهج الدراسية من المعيارية بجعل نصوص القرآن والسنة مرجعا في الدراسة إلى أن تكون بتريبية وتاريخية(55) بالاعتماد على نظريات العلوم الاجتماعية الغربية.

وعلى غراره تغير النموذج التعليمي من الشرق الأوسط وبالذات جامعة الأزهر إلى الجامعات الأوروبية، حيث قال أحد المفكرين: القبلة الجامعات الإسلامية النظامية بإندونيسيا قد تغيرت. وقد بدأ هذا التغيير بإرسال المدرسين لمواصلة دراستهم، لا إلى الشرق الأوسط ولكن إلى الجامعات في الأمريكا الشمالية، وإلى أوروبا وأستراليا. وهذا القرار ليس صدفة، وهو مخطط تخطيطا دقيقا من كبار رجال الحكومة بوزارة الشئون

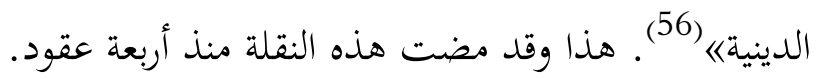
رابعا: الليبرالية في خطاب المثقفين:

سجل جريج بارتون أن بوادر النفوذ الليبرالي لدى المثقفين بإندونيسيا ترجع إلى الحركة الطلابية \اإتحاد الطلبة الإسلامية) الذي التحه نحو الفكر الحداثي منذ أواخر عقد الستينات للقرن العشرين، وجذب المثقفين الجدد من ذوي الخلفية التقليدية. وأصبح الابحاه بارزا في عهد رئاسة نور خالص ماجد (1939-2005) لهذا الاتحاد. فكان له دور بارز لنشر الاتحاه الليبرالي، وهو من طليعة هذه القافلة ومحرك لها. ولقد سجل بارتون أن

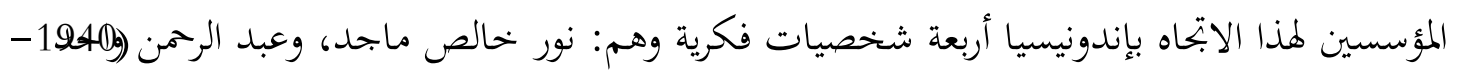
2009) ، وجوهان أفندي، وأحمد واهبرو1942-1973). وقد وصف بارتون بأن هؤلاء الأربعة مؤسسون للحركة .

(1) See: Amin Abdullah, Studi Agama : Normativitas atau Historisitas?(الدراسات الدينية: معيارية أم تاريخية?),p. 22, Yogyakarta: Pustaka Pelajar, 2004.

(م) Dekontruksi Islam Madzhab Ngaliyan:Pergulatan Pemikiran Anak

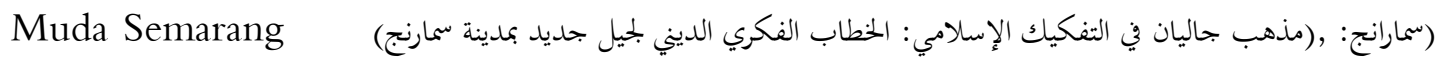
رسائل، 2005).

(57) Greg Barton, The Emergence of Neo Modernism, p. 84. 
هذا وقد ورث جيل عن جيل، فهناك مؤسس، فالمواصل، فجيل جديد. وقد كان الجيل الجديد أكثر جرأة في أطروحاتم الفكرية، ووثقوا شبكات عريضة سموها 》شبكات الإسام الليبراليه وهي بمثابة مظلة عقدية بين معتنقي الابحاه في أنحاء البلاد.

كان الاتحاه العام للإسلام الليبرالي كما وصفوه لأنفسهم هو: فتح باب الاجتهاد في جميع الجمالات، والتركيز على روح التدين وليس على المعاني الحرفية من النصوص، واعتناق الحقيقة النسبية المتفتحة والمتعددة، والتحيز إلى الأقلية المستضعفة، وإعلاء الحرية الدينية والعقدية، والفصل بين السلطة الدنياوية والأخروية وبين السلطة الدينية والسياسية(58)

وقد بحدت مؤسسة راند هذه المنظمة بأها حسب قوها: 》أكثر المنظمات المسلمة تحررا بدون خجل في إندونيسيا (وربما في كلجنوب شرق آسيا) هي شبكات الإسلام الليبرالي، والتي أنشأت1201 بواسطة شبابالمسلمين المثتفين والمتحررين، للتصدي على التأثير المتصاعد للحركة الجهادية والتطرف الإسلامي

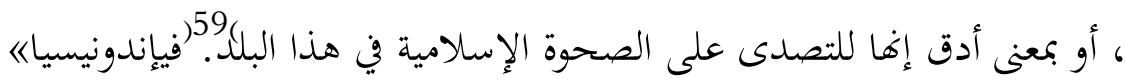
خامسا: الليبرالية الإندونيسية في المشروع الغربي:

أصدرت مؤسسة راند في هاية مارس 2007 تقريرا بعنوان 》بناء شبكات مسلمة معتدلة) وهو تقرير متمم لسلسلة التقارير التي بدأ هذا المركز الفكري في إصدارها Moderate Muslim Networks لتحديد الإطارات الفكرية للمواجهة مع العالم الإسلامي فيما بعد أحداث سبتمبير(60). 1. إندونيسيا كنموذج للمشروع الليبرالي:

هذا التقرير وصف الحالة الليبرالية في جنوب شرق آسيا -وبالخصوص في إندونيسيا- بأفا متميزة؛ حيث أكد على أهمية الاستفادة من التجربة الإندونيسية في إشاعة الليبرالية تحت مظلة الاعتدال، بمفهومه

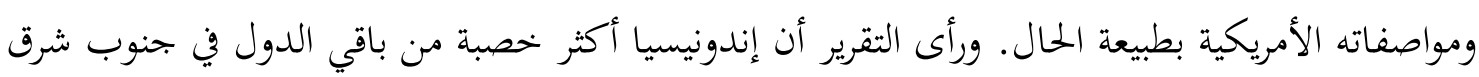
آسيا؛ لأن كلا من باكستان وماليزيا يمثلان التيار الأصولي من الناحية الفكرية، وإن كانت ماليزيا أقل تطرفا ولكنها في رأيه تتأثر بدرجة أكبر بالأزهر وبعلماء العالم العربي.

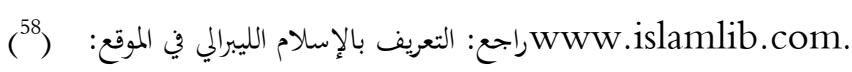

(19) Angel Rabasa, Building Moderate Muslim Network, p. 105.

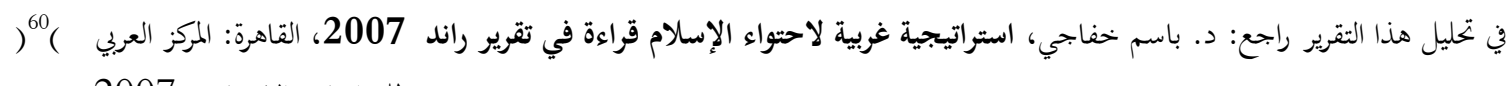
للدراسات الإنسانية، 2007. 
وقال التقرير: الوالخلاصة أن جنوب شرق آسيا لديه المؤسسات التعليمية الإسلامية المتطورة، ويمكن أن يكون مصدرا مهما في الحرب الدائرة حول الأفكار في العالم الإسلامي، وكذلك الجهود المتعلقة ببناء شبكات مسلمة معتدلة كما يقترح التقرير • وسوف تساهم هذه المؤسسة في بقاء المختمعات المسلمة في جنوب شرق آسيا ملتزمة بالقيم المعتدلة والشامخة رغم تعرضه للهجوم من الأفكار المتطرفة من الشرق الأوسط، وهذه المؤسسات يمكن أيضا أن تستخدم كلَبنات في شبكة المؤسسات التعليمية الإسلامية

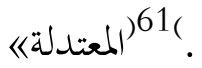

وفي سبيل ذلك رصد التقرير عددا من الجمعيات التي كانت أكثر خصبة لبناء المفاهيم الليبرالية الإسلامية مثل جمعية هضة العلماء والجمعية المحمدية وكذلك عدد من الجامعات الإسلامية وفي مقدمتها الجحامعة الإسلامية النظامية بجاكرتا.

2. 2 إندونيسيا كبوابة لاحتواء العالم الإسلامي:

وأكثر من ذلك وصف التقرير بأن إندونيسيا نموذج هام؛ لأن الليبراليين في نظرته قادرون على صياغة أجندة للحركة الفكرية والإعلامية حتى تخدم المعتدلين. ورأى أن التركيز على منطقة الشرق الأوسط هو استراتيجي

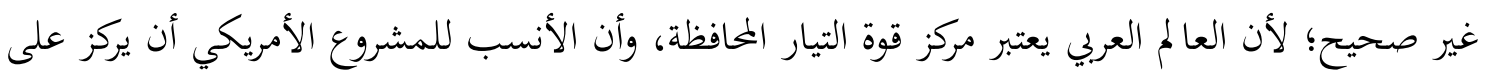
الأطراف، وليس على المركز. فقال التقرير: ارغم أن الكثير من المبادرات الغربية للتفاعل مع المسلمين تركز على منطقة الشرق الأوسط، فإننا نرى أن الشرق الأوسط وتحديدا العالم العربي، يمثل أرضا أقل خصوبة لمربة

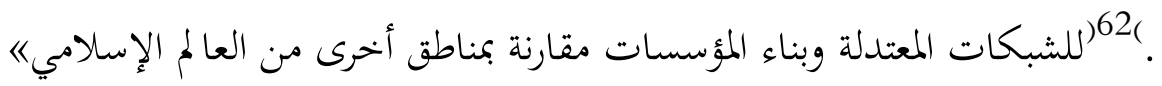

وعلى هذا فإن بناء مشروع الشبكات المسلمة المتعدلة يعتمد على محورين: الأول هو التعاون مع المعتدلين من العلمانيين في دول الأطراف، أو الدول التي يمكن العمل فيها بحرية، والثاني هو عكس مسار الأفكار بحيث تكون من الأطراف نحو المركز. قال التقرير: اإن الدافع الأساسي لتصورنا يعتمد على محورين: الأول هو العمل مع المسلمين المعتدلين في الدول التي تكون الظروف فيها متواتية وإيجابية لتطوير شبكات مسلمة معتدلة فعالة ومؤسسات من أجل تقوية هذه المحتمعات في مواجهة تدفق التفسيرات السلفية المتطرفة

( ${ }^{61}$ ) Angel Rabasa, Building Moderate Muslim Network, p. 109.

( ${ }^{62}$ Angel Rabasa, Building Moderate Muslim Network, p. 85. 
للإسلام والنابعة من الشرق الأوسط. المحور الثاني: هو إيجاد قنوات تواصل إعلامية تشجع نشر التفسيرات

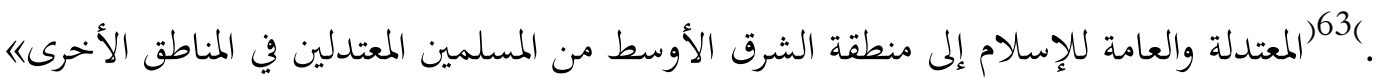

وهذا يعنى أن إندونيسيا تمثل بوابة طرفية لبناء شبكات ليبرالية مسلمة في العالم الإسلامي؛ حيث يسير هذا

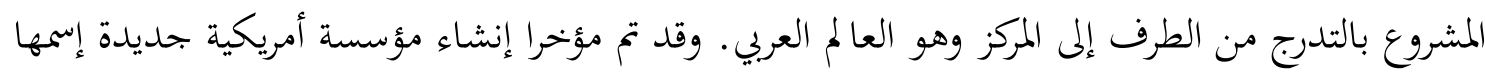

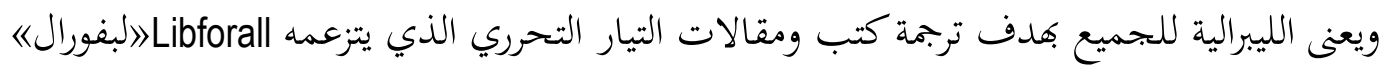

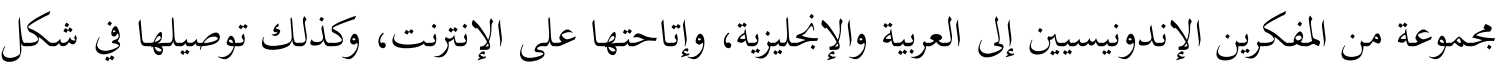

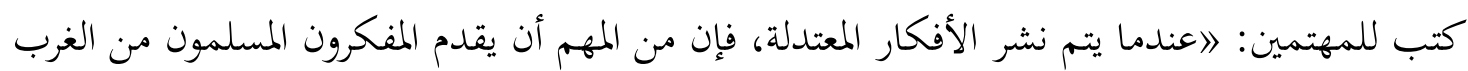

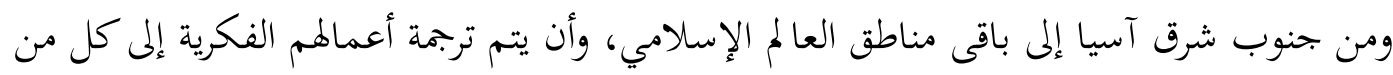

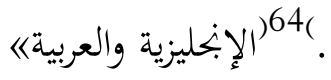

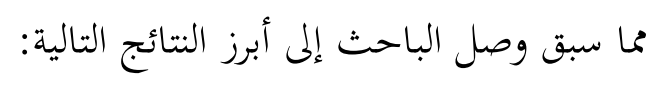

1. ظههور النظرة الليبرالية للإسلام في العالم الإسلامي له علاقة بالاستشراق، وكان له حافز ديني يتبلور في

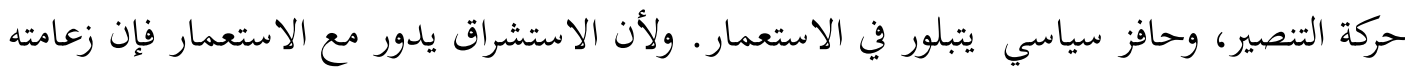

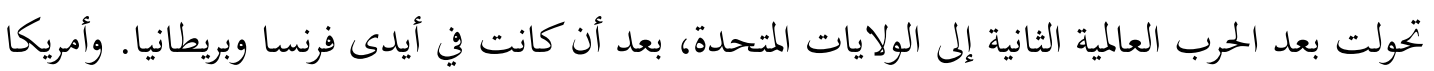

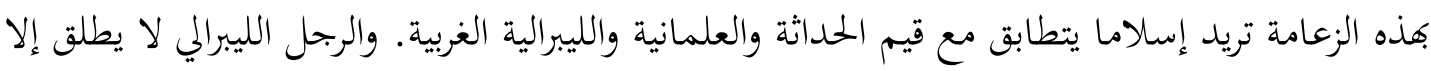
على من تحرر من العقيدة والخصائص الإسلامية، وبذلك لا تكون إلا ملحدة أو ارتيابية.

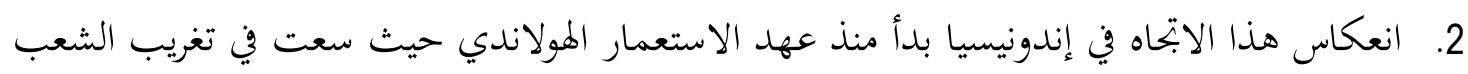

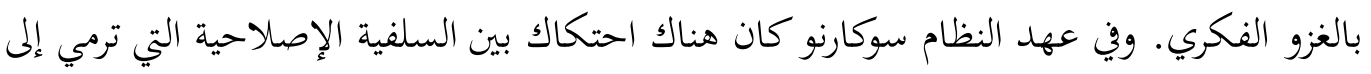

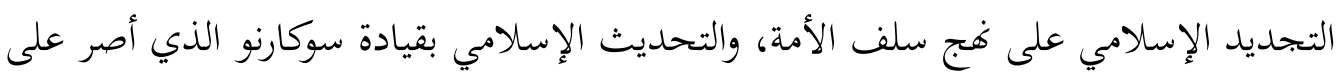

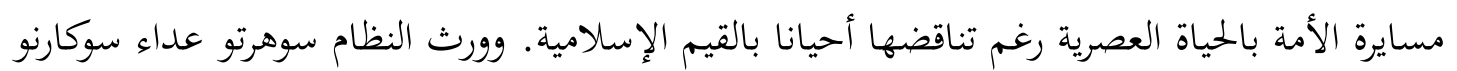

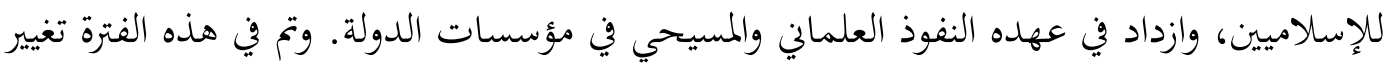

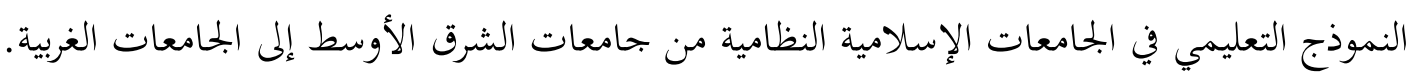

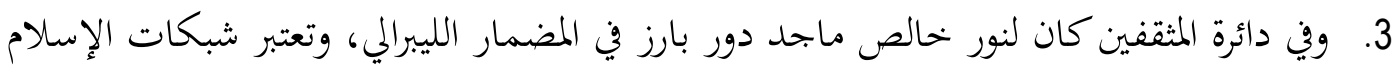
الليبرالي أهم منظمة ليبرالية في جنوب شرق آسيا ولديها شجاعة كبرى لتفكيك الثوابت الإسلامية، وفي

(33) Angel Rabasa, Building Moderate Muslim Network, p. 85.

(64) Angel Rabasa, Building Moderate Muslim Network, p. 88. 


$$
\text { نظر مؤسسة راند الأمريكية كان لهم إبجازات ثقافية، وأصبحت إندونيسيا في نظرها بوابة طرفية للسير }
$$

$$
\begin{aligned}
& \text { الدكتوراة في العقيدة والفلسفة بجامعة الأزهر بالقاهرة، محاضر بالدراسات العليا بجامعة ابن خلدون بوجور، } \\
& \text { والمركز الدراسي للشرق الأوسط والإسلام-الدراسات العليا-جامعة إندونيسيا بجاكرتا. }
\end{aligned}
$$

Albert Hourani, Arabic Thought in the Liberal Age 1798-1939, Indonesian Edition,translated by Suparno, Dahrits Setiawan, Bandung: Mizan, 2004.

Amin Abdullah, Studi Agama: Normativitas atau Historisitas? الدراسات الدينية: معيارية أم ) (تاريخية؟,Yogyakarta: Pustaka Pelajar, 2004.

Angel Rabasa And Others, Building Moderate Muslim Network, Pittsburgh: Rand Corporation, 2007

Azyumardi Azra, Jaringan Ulama Timur Tengah dan Kepulauan Nusantara Abad XVII dan XVIII (شبكات علماء الشرق الأوسط والجزر الإندونيسية في القرن السابع عشر والثامن عشر), p. 23-50, Bandung: Mizan, 1995.

Boland, B.J, The Struggle of Islam in Modern Indonesia (1945-1972), Indoenesian Edition (Pergumulan Islam di Indonesia 1945-1972, Jakarta: Grafiti, 1985.

Boland, The Struggle of Islam in Modern Indonesia, Indonesia Edition (Pergumulan Islam di Indonesia 1945-1970), translated by: Safroedin Bahar, Jakarta: Grafiti, 1985.

Fuad Jabali, Jamhari (ed.), Jamhari, IAIN dan Modernisasi Islam di Indonesia الجامعات الإسلامية) (النظامية وتحديث الإسلام بإندونيسيا), Jakarta : Logos, 2002.

Harry A. Poeze, Indonesian at Leiden University, in Indonesian and Islamic Studies, Zaini Muchtarom, Jacob Vredenbregt, E. Van Donzel (ed.), Jakarta: Indonesian Netherlands Cooperation in Islamic Studies (INIS), 1990.

Heru Cahyono, Soemitro dan Peristiwa 15 Januari 1974(سومترو وأحداث 15 يناير 1974), Jakarta: Pustaka Sinar Harapan, 1998.

The Earl of Cromer, Modern Egypt, Vol. II, p. 228-229, New York: Macmillan, 1908.

$$
\text { ، كويت: دار القلم، ط6، } 2003 .
$$


ابن خلدون ، مقلدمة ابن خلدون، بيروت: دار القلم، ط.5، 1984.

أبو الحسن الندوي، الصساع بين الفكرة الإسلامية والفكرة الغربية في الأقطار الإسلامي

Dekontruksi Islam Madzhab Ngaliyan:Pergulatan Pemikiran Anak Muda

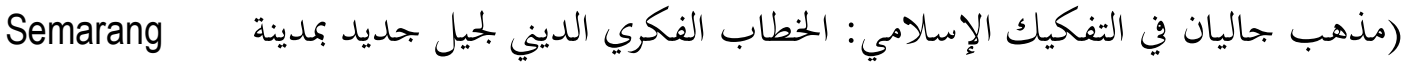
(سمارانج: رسائل، 2005).,سمارنج)

ادوارد سعيد، الامتثشراق المغاهيم الغربية للشرق ، المترجم: د. محمد عناني، القاهرة: رؤية للنشر والتوزيع، ط.1.، 2006.

الأمير شكيب أرسلان، الإسلام في جاواه وما جاورها ، إضافة لكتاب حاضر العالم الإسلامي للوترب ستودارد، ج1، بيروت: دار الفكر، د.ت.

باسم خفاجي، استراتيجية غربية لاحتواء الإسلام قراءة في تقرير راند ، القاهرة: المركز العربي للدراسات الإنسانية، 2007.

جابر قميحة، سيد قطب والإسلام الأمريكاني ، صحيفة آفاق عربية، في 27-12-2001؛ نقلا عن خخطوطة كتاب سيد قطب : أمريكا من الداخل ، التى نشرها سيد قطب في بحلة الرسالة الأسبوعية سنة 1951، 1952.

السيد جمال الدين الأفغاني والشيخ محمد عبده ، الآثار الكاملة العروة الوثقى ، ، إعداد وتقديع: سيد هادي خسرو شاهي، القاهرة: مكتبة الشروق الدولية، ط1، 2002.

طه حسين، مستثبل الثقافة في مصر، القاهرة: دار المعارف، 1938.

عبد الحميد ين عبد الجميد، مذكراتي السياسية، بيروت: مؤسسة الرسالة، ط1406. عبد الرحمن الميداني، أجنحة المكر الثلاثة وخوافيها، دمشق: دار القلم، ط.8، 2000. محمد البهي، الفكر الإسلامي الحديث وصلته بالا ستعمار الغوبي، القاهرة: مكتبة وهبة، ط. 14، 2005. محمد عمارة، الغزو الفكري وهم أم حقيقة؟، القاهرة: دار الشروق، ط2006،3. 
محمود حمدي زقزوق، الاستشراق والخحلفية الفكرية للصراع الحضاري، القاهرة: دار المعارف، د.ت.

مصطفي السباعي، الاستشسراق والمستشسقون ما لهم وما عليهم، القاهرة: دار السلام، ط1، 1998.

مورس بوكاي، التوراة والأناجيل والقرآن الكريم بمقياس العلم الحديث ، ترجمةعلى الجوهري، القاهرة: مكتبة القرآن، د.ت.

يوسف كرام، تاريخ الفلسفة الحلديثة، القاهرة: دار المعارف، ط.5، دت. 